\title{
CONSIDERAÇÕES SOBRE O FENÔMENO DA MEDICALIZAÇÃO NA INFÂNCIA À LUZ DA PSICANÁLISE
}

\author{
Emanuelle Pessanha GONÇALVES ${ }^{1}$ \\ Júlia Reis da Silva MENDONÇA²
}

\begin{abstract}
Resumo
Esse artigo tem como objetivo propor algumas reflexões sobre o fenômeno da medicalização na infância e sobre a influência dos discursos médico e científico no campo da Educação à luz da Psicanálise. Da mesma maneira, pretende-se pensar em um dispositivo psicanalítico - o IRDI - como forma de atuação de uma psicanálise em extensão junto ao campo educacional que se ofereça como alternativa ao processo de medicalização e como instrumento oportuno para pensar uma outra pedagogia que não mais exclua o sujeito. A contribuição da Psicanálise à Educação também tem como objetivo sensibilizar os educadores para a importância da intervenção precoce e de se considerar a subjetividade e potencialidades infantis no processo de aprendizagem.
\end{abstract}

Palavras-chave: Educação. Medicalização. Psicanálise.

\footnotetext{
${ }^{1}$ Pedagoga pela Universidade Federal Fluminense (UFF). Especialização em "Psicanálise Clínica: psicanálise com crianças - intervenção precoce” pela UCAM/SEPAI/RJ. Professora Orientadora Educacional da Rede Municipal de Ensino de Quissamã/RJ. ORCID: 0000-0002-9515-5181.

E-mail: nuellegon@gmail.com.

${ }^{2}$ Doutora em Psicologia pela Universidade Federal de Minas Gerais (UFMG). Mestre em Psicanálise pela Universidade Estadual do Rio de Janeiro (UERJ). Psicóloga. Psicanalista. Professora da Pós-graduação em Psicanálise Clínica: psicanálise com crianças e intervenção precoce pela UCAM/SEPAI/RJ. ORCID: 0000-0002-1011-1017. E-mail: juliareis2@yahoo.com.br.
} 


\title{
CONSIDERATIONS ABOUTH THE PHENOMENON OF CHILDHOOD MEDICALIZATION IN LIGHT OF PSYCHOANALYSIS
}

\author{
Emanuelle Pessanha GONÇALVES \\ Júlia Reis da Silva MENDONÇA
}

\begin{abstract}
This article aims to propose some reflections on the phenomenon of medicalization in childhood and on the influence of medical and scientific discourse in the field of education in the light of psychoanalysis. In the same way, it is intended to think about a psychoanalytic device - the IRDI - form of action of an extended psychoanalysis in the educational field that offers itself as an alternative to the medicalization process and as a convenient instrument to think of another pedagogy that no longer excludes the subject. The contribution of psychoanalysis to education also aims at making educators aware of the importance of early intervention and of considering children's subjectivity and potentialities in the learning process.
\end{abstract}

Keywords: Education. Medicalization. Psychoanalysis. 


\title{
CONSIDERACIONES SOBRE EL FENÓMENO DE LA MEDICALIZACIÓN EN LA INFANCIA A LA LUZ DEL PSICOANÁLISIS
}

\author{
Emanuelle Pessanha GONÇALVES \\ Júlia Reis da Silva MENDONÇA
}

\begin{abstract}
Resumen
Este artículo tiene como objetivo proponer algunas reflexiones sobre el fenómeno de la medicalización en la infancia y la influencia del discurso médico y científico en el ámbito de la educación a la luz del psicoanálisis. Del mismo modo, se pretende pensar en un dispositivo psicoanalítico -el IRDI- como forma de actuación de una extensión del psicoanálisis en el campo educativo que se ofrece como alternativa al proceso de medicalización y como instrumento oportuno para pensar en otra pedagogía que ya no excluya al sujeto. La contribución del psicoanálisis a la educación también pretende concienciar a los educadores sobre la importancia de la intervención temprana y de considerar la subjetividad y el potencial de los niños en el proceso de aprendizaje.
\end{abstract}

Palabras clave: Educación. Medicalización. Psicoanálisis. 


\section{Introdução}

Vem-se observando, no campo da atuação na educação pública, em uma rede municipal de ensino do Estado do Rio de Janeiro, um crescente aumento da influência do discurso das neurociências e das práticas inspiradas na psicologia cognitivo-comportamental e na psiquiatria biológica - ancorada na $5^{\text {a }}$ versão do DSM/Manual Diagnóstico e Estatístico de Transtornos Mentais, criado pela Associação de Psiquiatria Americana (APA). Podemos compreender esse fenômeno a partir da relação estabelecida entre o discurso médico - hegemônico no interior dos estabelecimentos de ensino - e a presença significativa da indústria farmacêutica. Da mesma forma, destaca-se uma forte valorização da nomeação diagnóstica como critério rígido e preponderante à prática inclusiva escolar, que, hoje, constitui um campo de pesquisa de enorme relevância social e ética.

No conjunto das atividades que a orientação educacional propõe-se a desenvolver como um marco identitário da profissão, levantamos questionamentos a respeito de alguns processos e procedimentos envolvendo a prática de acolhimento das queixas dos docentes em relação às inúmeras dificuldades e às características apresentadas por algumas crianças de até seis anos em situação de escolarização. Referimo-nos, por exemplo, à problemática das insistentes ações a que estamos submetidos de encaminhamentos para sucessivas avaliações das crianças junto à equipe de saúde mental e à equipe multidisciplinar da Educação, envolvendo - sobretudo - psicopedagogos, psicólogos e fonoaudiólogos com formações concatenadas com o discurso médico. A ideia é compreender como os educadores vêm fundamentando uma prática de educação inclusiva a partir, exclusivamente, de um discurso médico que não parece dar conta das vivências desiguais da infância e da complexidade dos fenômenos subjetivos inerentes ao processo educativo de modo que se faz necessário compreender melhor a forma como esse discurso médico comparece na escola, como esse discurso é legitimado pelos educadores e como, por conseguinte, se consolida como modelo determinante das práticas no interior das instituições educativas. Afinal, existem consequências éticas quando se estabelece que o laudo médico seja condição sine qua non para a escolarização, ou seja, quando o laudo é condição sem a qual a escolarização não é possível.

Um dos desafios encontrados na função da orientação educacional (PASCOAL; HONORATO; ALBUQUERQUE, 2008) tem sido o de sensibilizar o professor e toda a equipe escolar a olhar para a criança pela via da constituição do sujeito, fazendo com que esses profissionais estranhem menos essa criança e com ela possam dialogar mais diretamente, estando atentos à questão da organização psíquica e da intervenção precoce, segundo as contribuições psicanalíticas. De um modo geral, a formação dos educadores para o entendimento do 
desenvolvimento da criança não toca na questão da subjetividade e, muito menos, na questão da implicação do educador nesse processo de desenvolvimento da criança. Fazer com que o professor entenda a subjetivação do ponto de vista psicanalítico pode fazê-lo ampliar seu olhar para o desenvolvimento infantil e inibir procedimentos restritivos e classificatórios de avaliação e observação. Além disso, permite colocar esse educador em um lugar de implicação, de corresponsabilidade pelo que acontece à criança, não delegando - insistentemente - a terceiros, problemáticas que seriam de sua responsabilidade.

A resposta nominativa dos laudos médicos não diminui a angústia dos profissionais da Educação e não nos ajuda a enfrentar os desafios; apenas segue-se desconhecendo a condição e a complexidade da infância fora da lógica patologizante. Observamos que - sem o laudo - os educadores parecem não saber o que fazer com a criança. Os educadores se utilizam dos laudos psiquiátricos para, a partir destes, aplicar um conjunto de procedimentos autômatos que desconsidera a subjetividade das crianças e exclui os laços transferenciais, em contrapartida. Com base na noção de transferência ${ }^{3}$ proposta pela Psicanálise e aplicada ao campo da Educação, podese afirmar que a aprendizagem está para além dos conteúdos ensinados, mas advém da relação entre professor-aluno. Trata-se da escuta e do que se estimula - ou não - em relação ao que o aluno traz para a cena do aprendizado. É importante compreender, então, que o fenômeno da transferência pode ser observado “em diversas relações estabelecidas no decorrer de suas vidas. Trata-se de um fenômeno que é percebido em todas as relações humanas. Em uma relação qualquer em que não haja a figura do analista, a transferência pode se instalar e produzir efeitos reparáveis, tanto positivos quanto negativos” (RIBEIRO, 2014, p.25).

O que alimenta, inconscientemente, a angústia dos educadores, na medida em que a restrição ao laudo retira o lugar das potencialidades infantis no processo de aprendizagem tornando o fazer do educador ainda mais precarizado do mesmo modo que nos distancia da dimensão do inconsciente que nos habita e que designa nossa condição permanente de mal-estar. O furo, a falta, o resto e o enigma alçados à categoria conceitual que nos ajudam a compreender o processo de constituição do humano pela via da ética psicanalítica desaparecem no discurso pedagógico, dada a impossibilidade de se haver com a falta e com os restos que nos constituem e que quase sempre retornam sob a forma de sintoma.

\footnotetext{
${ }^{3}$ Freud (1912/1996) assinala que a transferência é uma (re)atualização de sentimentos à pessoa do médico ou a outra pessoa com a qual o sujeito se relaciona enquanto alteridade e que pode aparecer como uma apaixonada exigência de amor - transferência positiva - ou como resistência - transferência negativa.
} 
Ainda que se definam metas, objetivos, protocolos, regulações, métodos e estratégias de diagnóstico e avaliação no campo da Educação, há uma dificuldade em oferecer às crianças e às suas famílias algum lugar de reconhecimento enquanto sujeitos e não apenas como um transtorno pela via classificatória ou diagnóstica (VOLTOLINI, 2011). Estamos cada vez mais sendo compelidos a agir - menos como educadores e mais como diagnosticadores - no ambiente educativo. Desse modo, este artigo tem como objetivo problematizar a discussão acerca do fenômeno da medicalização e seus impactos na Educação, assim como pensar em saídas possíveis diante de tais impasses por meio da apresentação de uma proposta alternativa de um instrumento amparado em uma concepção psicanalítica: a metodologia IRDI - Instrumento Indicador de Risco para o Desenvolvimento Infantil. Mariotto e Pesaro (2018) esclarecem que o IRDI foi construído e validado a partir de estudos multicêntricos. Esclarecem ainda que o IRDI tinha como objetivo a criação de ferramentas para que os pediatras pudessem acompanhar o desenvolvimento psíquico de bebês e localizar possíveis problemas. A construção desses indicadores teve o aporte de um grupo de psicanalistas pesquisadores, coordenado pela professora Maria Cristina Machado Kupfer, o que tornou possível um trabalho de escuta psicanalítica junto aos profissionais da Educação que atuam com crianças.

\section{A medicalização generalizada, o predomínio do discurso da ciência na formação das subjetividades e seus impactos na Educação}

O fenômeno da patologização do processo de ensino-aprendizagem ou as relações entre medicalização e ensino não são recentes. No campo educacional, temos como exemplo a referência dos estudos da pedagoga Cecília Collares e da médica Maria Aparecida Moysés (MOYSÉS; COLLARES, 1997, 2015), que, há muitas décadas, empreendem estudos discutindo a respeito das explicações clássicas do fracasso escolar fundamentadas em um discurso médico patologizante, sobretudo, a associação entre dificuldades de escolarização e problemas neurológicos. Dogmas generalizados nos anos 1970 afirmavam que a causa dos altos índices de repetência estaria nas disfunções cerebrais mínimas, nas dislexias, nas disgrafias, nos distúrbios psicomotores etc. Da mesma forma, estudos expressivos acerca da produção social do fracasso escolar em escolas públicas foram realizados pela psicóloga Maria Helena Souza Patto (PATTO, 2015) - também uma referência importante no campo da Educação. Portanto, esse fenômeno já é conhecido e refutado, mas, de modo insistente, ainda é presente no cenário educacional. 
A medicalização marca um corte epistemológico sobre os excessos do alastramento da ‘jurisdição’ do campo da Medicina sobre problemáticas que dizem respeito ao campo das Ciências Humanas (DE CARLI; FILHO; CEZAR, 2020). Nota-se que a medicalização tem sido estudada por diversos pesquisadores pelas influências observadas nas diferentes áreas do saber da vida moderna. Há, portanto, uma difusão do saber médico no tecido social de maneira hegemônica, visando tratar temas complexos que deveriam ser olhados pelo viés de outros campos disciplinares, tais como: a Antropologia, a Sociologia, a História, a Ciência Política, a Psicologia, entre outros.

Percebe-se, na atualidade, a presença e a valorização das atividades vinculadas ao ato de diagnosticar, de modo que "na educação, diagnostica-se cada vez mais, e mais cedo. A medicalização da infância passou da disfunção cerebral mínima, nos anos 1970, para a dislexia, nos anos 1990, chegando agora ao déficit de atenção” (DUNKER, 2015, p. 20). Ao que tudo indica, essa inflação das práticas diagnósticas e os processos de medicalização da existência, amparados pelo discurso de uma psiquiatria organicista, seriam fomentados por um processo conhecido como a “morte da clínica psiquiátrica”. No que consistiria essa “morte da clínica” pelo olhar psicanalítico? Estaria o campo médico ciente das repercussões desse fenômeno no processo de medicalização excessiva da vida? Quais as especificidades do campo médico e do campo psicanalítico hoje? Caberia um diálogo entre essas disciplinas clínicas? Pode a instituição educativa, inserida nessa racionalidade diagnóstica contemporânea, se beneficiar desses debates? Essas são algumas reflexões importantes a serem levantadas.

A “morte da clínica psiquiátrica” poderia ser também expressa por uma incessante e gradual perda do diálogo “compreensivo” que constituía a base da entrevista e do diagnóstico psiquiátrico, sendo substituída por um anônimo e anódino protocolo e por uma entrevista que é mais demonstradora da doença, tomada como verdade preexistente, do que um momento de construção ou de incessante reconstrução de um saber (FILHO, 2001, p.25).

Segundo Bercherie (1989), a psiquiatria clássica foi caracterizada como uma clínica do olhar, na medida em que tinha como objetivo descrever e classificar os transtornos mentais com base na observação e descrição dos sintomas. Desse modo, o tratamento psiquiátrico se orientava tanto pela reinserção social do indivíduo como pela readequação de suas funções pragmáticas. Contudo, do século XIX ao século XX, em função do progresso da ciência e de fatores sociais e econômicos, a psiquiatria clássica foi sendo substituída por uma psiquiatria de orientação biológica, principalmente a partir dos anos de 1950, com os primeiros medicamentos psiquiátricos clorpromazina, imipramina, benzodiazepínicos - e com a elaboração do DSM. 
Ao mencionarmos a morte da clínica, observamos o quanto essa visão organicista engendrou um desinteresse pela fala do paciente enquanto instrumento de tratamento. Seus reflexos repercutem e se amplificam no campo da escolarização de crianças e têm sido um retrato da fusão entre as prescrições de um modo de fazer ciência e um pragmatismo econômico cada vez mais presente em nossa época. Ressaltamos que a crítica se concentra nesta fusão entre uma psiquiatria mais remetida ao campo biológico - que exclui processos mais complexos de entendimento da subjetividade - e os interesses do capital, sem, no entanto, desconsiderar as contribuições da psicofarmacologia, das técnicas de neuroimagem ou das neurociências em contextos específicos onde a medicina atua.

Pesquisas de diferentes campos disciplinares (DUNKER, 2015; LAIA, 2011; MOYSÉS, M; COLLARES, 1997) apontam para uma substituição das práticas clínicas pautadas na palavra em favor da administração massiva e, por vezes, exclusiva da medicação. Assim, a partir de protocolos simples, padroniza-se o diagnóstico e a medicalização (DUNKER, 2015). Desse modo, observamos que, nas universidades, nos cursos acadêmicos de formação em Medicina e Psiquiatria, parece haver uma preocupação em suprimir a trajetória singular dos pacientes em detrimento dos questionários e dos protocolos. Os educadores também não ficam fora desse modo de operar, pois são influenciados pela atuação dos experts dos referidos campos e pela fragilização simbólica própria do seu campo de saber-fazer. O psicanalista e psiquiatra Marcelo Veras (2018, p.155) profere o que, de certa forma, podemos tomar a “morte da clínica” na perspectiva reflexiva da psicanálise, trazendo-nos - em sua discursividade - o embate entre esses modos de operar. O autor nos fala da pulverização sofrida pela Psicanálise, pela Psicologia e pela Psiquiatria em função das neurociências:

Enquanto uma parte cada vez mais crescente da psiquiatria e da psicologia desenvolveu uma verdadeira aversão à subjetividade, buscando critérios que eliminem o sujeito e reforcem a cientificidade pautada no caráter orgânico dos comportamentos, a psicanálise buscou sua secularização na investigação do mal-estar instaurado pela inadequação da linguagem ao corpo biológico (VERAS, 2018, p.155).

A Psicanálise coloca-se, então, como um dos campos disciplinares mais ricos e propositores na ampliação desse debate. Conforme assinala Dunker (2015, p.24):

Considerar o diagnóstico em psicanálise reconstrução de uma forma de vida envolve tanto a diagnóstica do sujeito como a transversalidade diagnóstica entre disciplinas clínicas (médica, psicanalítica, psiquiátrica, psicológica); tanto a flutuação discursiva dos efeitos diagnósticos (jurídico, econômico, moral) como sua incidência no real das diferenças sociais (gênero, classe, sexualidade). Reconstruir uma forma de vida, no escopo ético de uma racionalidade diagnóstica pensada dessa maneira ampliada, é, no fundo, refazer os laços entre trabalho, linguagem e desejo, pensando a patologia - que se exprime no sintoma, no malestar e no sofrimento - como uma patologia do social. 
Dunker (2015) nos alerta, ainda, para a absorção dos efeitos dos diagnósticos no interior da prática clínica e - aqui ousamos dizer - também das práticas de escolarização, compreendidas como práticas sociais. O diagnóstico não é apenas um fato clínico na medida em que pode, da mesma forma, se tornar um fato econômico, um problema moral, um problema educacional, um fato jurídico, um fato epidemiológico e, potencialmente, um fato psicológico. Precisamos estar atentos a essa composição dos efeitos e sentidos de um diagnóstico para um sujeito ou para uma comunidade diante do aspecto social de sua patologia, a que o autor chamou de "diagnóstica”.

Neste artigo, pontuamos, destarte, o fenômeno da medicalização numa acepção mais ampla, sobretudo, pensando na dinâmica diagnóstica envolvendo o sujeito-criança no ambiente da escola. Recuperamos aqui o conceito de "iatrogênese” presente nesses processos de medicalização em ambiente escolar. Tal conceito designa que, a partir dos diagnósticos incutidos, do estigma e do rótulo impregnado na criança, aquelas características preditas nos critérios diagnósticos até então abstrações separadas do indivíduo passam a tomar vida, a se concretizarem neste indivíduo (ORRÚ, 2016).

No campo da Educação, de um modo geral, vivenciamos cotidianamente uma profunda precariedade na escuta dos sujeitos-criança na mesma proporção em que se dá uma carência do suporte da cultura e do simbólico na atuação do ofício do professor. Os educadores se mostram vulneráveis ao discurso da Ciência. Vulnerabilidade que pode ser compreendida como sintoma da própria precarização simbólica, social, cultural e material na qual a profissão está imersa historicamente (REIS; CECÍLIO, 2014).

Vemos, por exemplo, ressurgir a patologização do fracasso escolar como sintoma individual, fomentando práticas e processos de exclusão e objetalização das infâncias, sem considerar sua relação com algumas práticas e processos escolares que podem contribuir para uma dificuldade de aprendizagem (PATTO, 1997) de modo que as crianças são protocoladas, testadas e fichadas desde tenra idade como “patológicas”, “anormais” ou mesmo como “doentes mentais”.

É cada vez mais presente a influência das neurociências no fazer da psiquiatria de orientação biológica, das psicologias de orientação comportamental e das práticas psicopedagógicas e fonoaudiológicas e das terapias ocupacionais que seguem essas tendências. Esses são alguns dos principais profissionais a dialogarem com os professores mediante o enigmático que habita seu ofício. Portanto é perceptível o impacto dessa discursividade no imaginário social e cultural. O caminho vigente na educação de crianças na perspectiva inclusiva tem sido o da disseminação de diagnósticos psiquiátricos, o de uso de psicofármacos e o das práticas cognitivas. (ANGELUCCI, 2014). 
O sujeito da educação parece estar fundido preferencialmente ao sujeito da ciência biomédica e distante do sujeito do inconsciente da psicanálise. De que sujeito falamos, portanto, e qual projeto se tem construído para se pensar a formação humana nas escolas brasileiras? Por quais motivos se popularizam e se amplificam os métodos e as teorias fundidas ao discurso biomédico na formação profissional dos que atuam com Educação? Essas são questões relevantes que precisamos considerar.

Recorremos às palavras de Mello (2014) ao descrever a sensibilidade e o trabalho da psiquiatra brasileira Nise da Silveira, pensando sobre o lugar que os laudos médicos vêm ocupando na escola. Laudos esses que destituem a criança de seu lugar de reconhecimento. Segundo Mello (2014, p. 185):

Nos relatos de casos clínicos feitos por ela, em vez dos amontoados de sintomas encontrados habitualmente nos prontuários psiquiátricos, iam sendo descortinados histórias humanas densas, nas quais, apesar da dissociação, ainda havia um sentido pleno de vida e emoções.

Sendo assim, observamos que as histórias de vidas e os modos singulares de operação psíquica diante das contingências da vida das crianças têm sido desconsiderados e que poderiam ser observados e servir de matéria para a subjetivação em situações escolares. Afinal, devemos estar atentos à carência de identificações simbólicas que, porventura, podemos alimentar na criança no ambiente da escola. Criança esta que precisa encontrar um lugar que a sustente como sujeito do desejo.

Vemos, claramente, o quanto a preponderância da nomeação normativa de um sintoma reduz ou inviabiliza a experiência expressiva de uma criança diante de seu professor em um processo educativo. Proliferam-se ideias, se disseminam crenças de que apenas pelo diagnóstico clínico e com a medicalização da criança conseguiremos pensar em um plano de inclusão, com planejamento das atividades pedagógicas envolvendo adaptações curriculares, delimitação de um tempo de permanência do aluno no ambiente escolar, de processos avaliativos e de condutas de interações:

Das crianças ditas 'normais' é esperado que se comportem 'normalmente' ou 'naturalmente', 'como todas as outras', como as crianças de sua idade, que aceitem bem as intervenções educativas sem grande resistência. Há ainda expectativas relacionadas ao gênero, à condição social e ao grupo cultural, todas incluídas em uma 'etiqueta' que classifica os alunos de modo preconcebido. Aqueles com alguma deficiência recebem, além de um rótulo que os nomeia, um protocolo de procedimentos e expectativas ajustados ao caso (REZENDE; SÁ, 2018, p.210).

Com a influência das pesquisas envolvendo os psicofármacos, seu uso na clínica médica, na formação dos profissionais da área e nos seus modos de concepção da doença mental, acentuou-se a prática da medicalização da Psiquiatria. Essa se afastou da Filosofia, da Sociologia e da Psicanálise para recuperar seu prestígio junto à Medicina, dando início à ideia de construção de um manual que 
fosse universal, classificatório, descritivo, objetivo e pretensamente ateórico, estando vinculado aos investimentos da indústria farmacêutica. Com o empobrecimento da clínica após o DSM III e o abandono de toda a perspectiva psicanalítica e fenomenológica na Psiquiatria, criou-se um terreno bastante fértil para o fenômeno da medicalização (AGUIAR; LAIA, 2017). Foi a partir do DSM III (1980) que houve uma ruptura com o embasamento teórico - até então de inspiração psicanalítica. Ao longo da história, na constituição dos Manuais de Estatísticas Diagnósticos (DSMs), esse sucessivo e gradual afastamento dos princípios conceituais da Psicanálise vem corroborando, paulatinamente, com a inflação dos diagnósticos, ou seja, com o desaparecimento das estruturas clínicas e da multiplicação dos transtornos e síndromes. Daí o fato de nos reconhecermos, qualquer um de nós, muito facilmente, nas classificações clínicas dotadas de valor diagnóstico.

Os conceitos do DSM 5 parecem também ter se popularizado e se disseminado na sociedade, não estando mais restritos ao campo da Medicina. Hoje, muito facilmente, vemos pedagogos e psicopedagogos debruçados em cima de um Manual de Estatísticas de Diagnóstico, proferindo um conjunto de letras e números pretensamente definidores identitários do seu alunado e contribuindo para um processo conhecido como "fatores iatrogênicos", já citados acima. O vasto sistema psicológico, com ênfase na noção de inconsciente - que reorganizou a psicopatologia em torno das categorias neurose, psicose e perversão -, deixou de existir, bem como a subjetividade - literalmente varrida do DSM 5. Todo esse esforço fora uma tentativa de buscar realinhar a Psiquiatria ao campo da Medicina.

A Psicanálise e a Psiquiatria formam, hoje, distintos campos do saber, com teorias e epistemologias muito próprias, mas que, do ponto de vista ético da clínica, deveriam se fazer dialogar. O sujeito que comparece à clínica médica e/ou à clínica psicanalítica se apresenta mergulhado ou atravessado tanto pela realidade dos psicofármacos quanto pela presença e manifestação atemporal do seu inconsciente. No ambiente escolar, não se faz diferente. Alguns estudiosos do campo da Psiquiatria, atravessados pela Psicanálise, (LIMA, 2005; AGUIAR, 2004) defendem que nem a causalidade psíquica nem a genética podem ser concebidas como determinação absoluta para as questões envolvendo a compreensão das formas do sofrimento e da diversidade humana. É preciso buscar caminhos explicativos mais condizentes com a complexidade inerente ao sofrimento psíquico, inerente à condição humana e inerente à própria complexidade do tema da medicalização na medida em que não constitui tarefa fácil a compreensão dos embates envolvendo esses dois campos do saber: a Psicanálise e a Psiquiatria. 
Observa-se uma significativa produção de pesquisas acadêmicas envolvendo o fenômeno da medicalização, inclusive, no âmbito das instituições escolares (COLLARES; MOYSÉS, 1996; PATTO, 2015). Na Educação, esse fenômeno tem perpassado; sobretudo, as práticas envolvendo alunos da política de inclusão. Políticas estas que se mostram um tanto paradoxais no trato com o tema da inclusão educacional. É comum presenciarmos uma dependência entre inclusão e produção diagnóstica médica, ou seja, o laudo médico se apresenta como “objeto” determinante na legitimação da inclusão e escolarização dos alunos. As nossas políticas de inclusão determinantes do público-alvo da educação especial são permeadas por conceitos e terminologias do campo médico. No entanto, o Ministério da Educação, em seus dispositivos jurídicos, assegura que o laudo médico não é imprescindível, não é obrigatório para assegurar o atendimento educacional especializado, pois se trata de ofertar um trabalho no âmbito pedagógico e não clínico (FONSECA, 2017).

Consideramos necessário recuperar a noção de psicopatologia trazida por Dunker (2015) que se opõe a uma elisão do sujeito e supressão do debate hermenêutico que os diagnósticos propostos pelos manuais tipo DSM e CID-10 implementam (FONSECA, 2017). Adentramos, portanto, ao campo psicopatológico, ou seja, o papel da psicopatologia nas práticas inclusivas atuais. Segundo Safatle (2013, p. 22), “a psiquiatria atual se coloca cada vez mais orientada pela perspectiva das evidências, que 'privilegia fenômenos mensuráveis, quantificáveis e claramente diferenciáveis através de um conjunto finito e operacional de características de base”". Desse modo, "trata-se de uma psiquiatria de caráter universalizante” (SAFATLE, 2013, p.22).

As práticas educativas - sobretudo, as práticas psicopedagógicas atravessadas pelo discurso das neurociências - parecem embebidas de um paradigma do mensurável, um claro marcador da presença de uma roupagem cientificista que, muitas vezes, não reconhece a diferença e a singularidade que escapa às categorizações e às nomenclaturas psiquiátricas. Ou seja, trata-se de um projeto universalizante que não responde ao sujeito de desejo e sua singular incompletude. Assumir essa noção de eficiência, defendida muitas vezes pelo discurso da Ciência, seria incluir um reducionismo em sua prática, como nos coloca Barton, pois é impossível traduzir o sofrimento psíquico (BRITO, 2017, p.194). Ainda que Freud, o fundador da Psicanálise, tenha afirmado que a educação é uma das três tarefas ou atividades impossíveis, ao lado de governar e psicanalisar, ela pode ser realizada através de uma profunda "reflexão sobre o que é ensinar e o que é aprender" (RIBEIRO, 2014, p.24). 
Aquilo que escapa à ciência é o que interessa para o campo psicanalítico, de modo que Freud inventa um método que se propõe a trabalhar ou investigar o que falha e o que faz sintoma para cada sujeito (ANSERMET, 2013). Temos diante de nós a criança que se faz presente como diferença, não como doença, mas como enigma. Dimensão trágico-enigmática que fundamentará toda a ética psicanalítica e que a fará distinta do saber médico.

\section{Soluções possíveis ao fenômeno da medicalização}

As críticas à medicalização no ambiente escolar já são frutos de debates amadurecidos e largamente estudados e difundidos no meio acadêmico como as pesquisas empreendidas por Maria Aparecida Moyses, Cecília Collares e Maria Helena Souza Pato. As escolas são instituições sociais inseridas no interior das práticas mercantilizadas de troca humana, vulneráveis ao estatuto do saber médico na modernidade, fruto de consequências das transformações próprias a esse contexto histórico, especialmente no que diz respeito ao lugar ocupado pela tecnologia científica no mundo moderno, bem como as mudanças ocorridas nos campos da ética e da política (GUARIDO; VOLTOLINI; 2009). Portanto, a proposição alternativa e viável a esse fenômeno - brevemente apresentada aqui - é, também, um modo de se pensar a respeito da inserção da Psicanálise nos debates da esfera pública. Não falamos de uma psicanálise pura, mas de uma psicanálise aplicada na interseção com a clínica em seus diversos âmbitos. Referimo-nos à importância de se encontrar um lugar no mundo para a Psicanálise na articulação com outros saberes e discursos (ALBERTI, 2011).

É disso que se trata este artigo: pensar uma Psicanálise em extensão no diálogo com a Educação, interrogando a Pedagogia no trato com a complexa temática da medicalização. Falamos, portanto, de uma perspectiva política, da interseção entre a psicanálise e a justiça social, por exemplo. Como se sabe, Freud apoiou as clínicas psicanalíticas gratuitas, lutou por honorários flexíveis e defendeu a prática da análise leiga - todos eles desvios substanciais de uma tradição de privilégio dos médicos e de dependência dos seus pacientes (DANTO, 2019).

Sabemos que, em meio às crises constantes na educação pública brasileira e a desvalorização material e simbólica do ofício de professor no âmbito das esferas, sobretudo, Estadual e Municipal, encontramos debates profícuos encabeçados pela Psicanálise nessa interface com a Educação (VOLTOLINI, 2011; CARNEIRO, 2018; FRANCO, 1999), o que enriquece as discussões a respeito da medicalização e que propõe caminhos e possibilidades para a sua superação ou 
oportunidades enriquecedoras de diálogo. Os dispositivos propostos a partir da Psicanálise - como o IRDI - abrem possibilidades de intervenção no social seguindo a ética psicanalítica. Freud (1919/1996), em seu texto “Linhas de Progresso na Terapia Psicanalítica”, esmiúça a estrutura interna de funcionamento do procedimento terapêutico da psicanálise, apontando, de maneira visionária, a função social da mesma e atribuindo ao Estado um importante papel intervencionista. Ainda nesse texto, Freud (1919/1996) ressalta a importância de ampliar a terapêutica psicanalítica à massa da população assolada por quadros graves de neurose, somado às precárias condições materiais, demonstrando sua preocupação de cunho social:

\begin{abstract}
Vamos presumir que, por meio de algum tipo de organização, consigamos aumentar os nossos números em medida suficiente para tratar uma considerável massa da população. Por outro lado, é possível prever que, mais cedo ou mais tarde, a consciência da sociedade despertará, e lembrar-se-á de que o pobre tem exatamente tanto direito a uma assistência à sua mente, quando o tem, agora, à ajuda oferecida pela cirurgia, e de que as neuroses ameaçam a saúde pública não menos do que a tuberculose, de que, como esta, também não podem ser deixadas aos cuidados impotentes de membros individuais da comunidade (FREUD, 1919/1996, p.7).
\end{abstract}

Pretendemos pensar e propor aqui, de maneira breve, um dispositivo inspirado na Psicanálise que, de certa forma, nos coloca no enfrentamento de tais questões. O uso do IRDI nos auxilia a olhar para o infamiliar de cada um, para o mal-entendido, para o mal-estar na Educação. Seria um dispositivo de oferta à palavra e uma possibilidade de compreensão da categoria do sofrimento psíquico nas quais os educadores se encontram cotidianamente envolvidos. Dispositivo ainda pouco conhecido entre os educadores, mas que se traduz em uma metodologia de trabalho importante no fomento à mudança paradigmática do nocivo fenômeno da medicalização da Educação. Trata-se de construir saídas singulares e criativas para cada situação de inclusão, sem deixar de contemplar suas especificidades e diferenças. Para tanto, faz-se necessário superar o medo frente ao desconhecido ou frente ao que se apresenta como intraduzível e também suportar a falta de tudo-poder saber sobre o outro (CAVALLARI, 2014, p.263).

O IRDI surgiu a partir de uma demanda específica de trabalho proposto por membros da consultoria da área da Saúde da Criança do Ministério da Saúde à professora Maria Cristina Kupfer, docente do Instituto de Psicologia da Universidade de São Paulo (IPUSB). A ideia era iniciar a revisão do manual denominado: "Saúde da Criança: acompanhamento para o crescimento e desenvolvimento infantil”, incluindo nele indicadores de desenvolvimento psíquico: “o pedido de inclusão do desenvolvimento psíquico era então precisamente um pedido de inclusão da perspectiva da psicanálise em um documento de orientação para os pediatras de todo o Brasil” (BERNARDINO; KUPFER, 2018, p. 63). As consultoras da área da saúde na ocasião já tinham 
algum vínculo de formação com o campo psicanalítico. Os indicadores de desenvolvimento psíquico foram sendo incluídos na Caderneta de Saúde da Criança, que, a partir da versão de 2017, contém mais de cem páginas.

Para adequar-se às orientações das políticas públicas de Saúde, ter os indicadores validados e os incluir nas práticas diárias envolvendo as ações dos pediatras, a pesquisa psicanalítica com os indicadores teve que realizar algumas adaptações e concessões, seguindo alguns princípios do paradigma da ciência médica. A própria ideia de “risco" é importada da área médica e não originária do campo psicanalítico. As adaptações realizadas nunca comprometeram a especificidade do trabalho de inspiração psicanalítica, já que a maior preocupação era inserir - na documentação e nas ações práticas de profissionais da Saúde - uma preocupação, uma compreensão com a vida psíquica do bebê e do sofrimento que poderia surgir do encontro e desencontro com seus cuidadores. Indicadores estes que sinalizariam problemas na constituição do sujeito. Bernardino e Kupfer (2018) assinalam que trinta e um indicadores foram selecionados a partir de muitos debates, experimentações e pesquisas entre os intelectuais envolvidos, como Julieta Jerusalinsky, Amira Figueiras, Rosa Maria Mariotto e Rogério Lerner. O IRDI não nasceu, portanto, da preocupação de ser um instrumento de diagnóstico focado na doença como comumente o saber médico se organiza, mas sim orientado para a detecção de sofrimento psíquico na primeiríssima infância. Da mesma forma, busca pensar modos possíveis de intervenção que assegurem as condições para que um bebê possa se constituir como um sujeito desejante e busca trazer o tema da intervenção precoce, ou a tempo, para o campo da Educação.

No âmbito da prática psicanalítica com crianças, a intervenção precoce diz respeito às possibilidades de se fomentar uma constituição subjetiva que, porventura, possa estar dificultada ou inexistente. Essa ideia está atrelada aos casos de crianças com sinais precoces de isolamento autístico, ainda que o IRDI não se limite a tais questões, pois nos permite trabalhar com as formas distintas de sofrimento humano.

Assim, embora o IRDI tenha nascido de uma demanda específica do campo da Saúde Pública e direcionado às práticas dos pediatras objetivando a identificação do sofrimento psíquico em bebês durante consultas médicas na atenção básica, tal metodologia vem sendo utilizada no campo educacional "como uma ferramenta de prevenção e promoção da saúde mental em bebês, ao propiciar as condições para o surgimento de um enlace do professor com o bebê" (MARIOTTO; PESARO, 2018, p.106). Apesar da aceitação da pesquisa, os pediatras se utilizam pouco ou quase nada desse instrumento, dado, talvez, ao fator inibidor da própria formação acadêmica dos médicos. 
O IRDI pode ser concebido não como um instrumento, um protocolo frio e abstrato, mas como uma ação motivadora de uma prosa - como nos relata Rosa Maria Mariotto, uma das pesquisadoras envolvidas com o desenvolvimento e aplicação do IRDI - que possibilita a circulação de um discurso a respeito da criança no sentido de alargar o olhar que o professor tem em relação ao que pode ser compreendido como desenvolvimento de uma criança.

Muitas vezes os professores sabem que alguma coisa não vai bem com um bebê, mas quase sempre não sabem o que fazer com isso, não conseguem nomear, dar um lugar no discurso para isso, ou seja, não encontram uma rede de significantes que dê lugar para essas vivências. O que acontece? Neste momento, muitos encaminhamentos para avaliação da criança são direcionados para uma equipe externa à escola e o professor deixa de se responsabilizar pelo que aparece diante de si. O professor deixa de se implicar, ou melhor, deixa de compreender que o modo como esse bebê funciona no ambiente da creche tem relação com o modo como ele, educador, se ocupa desse bebê. Esse modo de se implicar nas questões que surgem no ambiente escolar está relacionado, também, a capacidade de oferecer uma escuta sensível (para além das queixas) e a uma investigação cuidadosa que reveste todo o trabalho de um educador "suficientemente bom", tomando de empréstimo a expressão de Winnicott “mãe suficientemente boa” (WINNICOTT, 2020, p. 160).

O IRDI acaba, da mesma forma, por indagar a Pedagogia ao afirmar que quanto mais se pretende fazer uma educação escolarizante para os bebês, com um excesso de pedagogização, se exclui a dimensão subjetiva tanto da criança como do professor. O professor acaba se transformando em um técnico, distanciado da percepção de que seja alguém que marca essa criança, ou seja, o educador pode tomar esse bebê como sujeito ou não. Isso dependerá de como ele olha esse bebê, do modo como ele se dirige a esse bebê, do modo como ele se ocupa do corpo desse bebê e de como ele conversa, ou não, com esse bebê. O IRDI convoca o educador não só à responsabilização pedagógica, mas também à sua responsabilização subjetivante. Como nos alerta Jacques Lacan (1986) em seu texto "Duas notas sobre a criança”, para que haja a constituição subjetiva de uma criança se faz necessário um desejo que não seja anônimo, ou seja, que o cuidado não seja anônimo. Assim, faz-se importante que o educador possa estabelecer laços com essas pequenas crianças de forma singular, peculiar, da atenção do um a um.

Desse modo, o IRDI apresenta outra noção de cuidado e de prevenção, seguindo outra lógica operativa. De acordo com Maria Eugênia Pesaro et al. (2012, p. 255), comumente, a prevenção é colocada como "uma intervenção para se evitar o que não se quer, o indesejável. Ou seja, a 
prevenção relacionada aos conceitos de evitar o mal, inibir causas patológicas, a noção de probabilidade e previsão, também relacionada a um ideal”.

O IRDI não se constitui, portanto, como um verificador de ausências no desenvolvimento infantil, mas como um roteiro de leitura, de acompanhamento do desenvolvimento, fazendo com que a dimensão psíquica ganhe representatividade frente a outras investigações hegemônicas tais como a neurológica ou a motora. O IRDI se coloca como uma metodologia de pesquisa e de trabalho bastante provocativa e alentadora frente aos desafios da Educação e dos muitos mal-estares próprios a esse campo. A Psicanálise não traz respostas prontas, universalizantes, nem tampouco idealizações a respeito dos sujeitos e dos processos de escolarização, mas traz, com rigor, um (não)saber que permite situar os sujeitos como sujeitos do inconsciente, do desejo, da pulsão e da linguagem.

\section{Considerações finais}

Este artigo tem como proposta central apresentar algumas ideias a respeito do cenário da medicalização e alguns de seus efeitos na Educação, mais precisamente na de crianças pequenas público-alvo da educação infantil, da faixa etária de zero a seis anos. Ao longo do artigo foi possível destacar, portanto, os prejuízos oriundos da introjeção do discurso médico no interior das instituições educativas, sendo um acentuador do reflexo do esvaziamento simbólico do ofício e da desconsideração da subjetividade da criança na medida em que tomamos o conceito de sujeito para a Psicanálise como aquele que se constitui na relação com o Outro da linguagem e é marcado, estruturalmente, tanto pela falta como por sua capacidade de desejar.

Diante do desafiante e complexo fenômeno da medicalização que se espraia pela Educação, apresentamos a força do instrumento do IRDI, inspirado pelo campo de saber da Psicanálise, que se mostra viável ao campo da Educação para se pensar o tema da inclusão de crianças em situação de sofrimento psíquico.

Sem sombra de dúvida, faz-se importante, enquanto educadores, alargar a nossa percepção acerca do desenvolvimento infantil, aprendermos a lidar com a diversidade e repensarmos o ideário pedagógico da preponderância das práticas hegemônicas e universalistas. Somos convidados pela Psicanálise e por alguns dispositivos criados, como o IRDI, a manter o olhar sobre a singularidade e a pensar a relação entre o 'para todos' e 'o cada um’ no contexto das práticas pedagógicas. Atravessados pela Psicanálise, lançamo-nos ao exercício da indignação, pois ela é fundamental para a transformação que pretendemos engendrar. 


\section{Referências}

ANGELUCCI, C. B. Medicalização das Diferenças Funcionais - continuísmos nas justificativas de uma Educação Especial subordinada aos diagnósticos. In: Nuances: estudos sobre Educação, Presidente Prudente/SP, v. 25, n. 1, p. 116-134, jan./abr. 2014. Disponível em: https://revista.fct.unesp.br/index.php/Nuances/article/view/2745/2521. Acesso em: 12 jun. 2021.

ALBERTI, S. Psicanálise e intervenção no campo social. In: Psicanálise, universidade e Sociedade. Rio de Janeiro: Cia de Freud, 2011.

AGUIAR, A.A. A psiquiatria no divã: entre as ciências da vida e a medicalização da existência. Rio de Janeiro: Relume Dumará, 2004.

ANSERMET, F. A irredutível singularidade entre ciência e psicanálise. In: A ordem simbólica no século XXI: não é mais o que era. Quais as consequências para o tratamento? Rio de Janeiro: Subversos, 2013.

AGUIAR, A. A.; LAIA, S. Enigma, objetivação e diluição da loucura. In: Psicopatologia Lacaniana I. Organizadores: Antônio Teixeira e Heloisa Caldas. Belo Horizonte: Autêntica, 2017.

BERCHERIE, P. Los fundamentos de la clínica: historia y estrutura del saber psiquiátrico. Ed. Manantial, 1989.

BERNARDINO, L. M. F.; KUPFER, M. C. M. IRDI: um instrumento que leva a psicanálise à polis. In: Estilos Clin., São Paulo, v.23, n.1, 2018.

BRITO, B. P. M. Diagnóstico diferencial: a aposta na singularidade em tempos de medicalização do sofrimento. In: Subjetividade, Clínica e Política. Eduff: Niterói - RJ, 2017.

CAVALLARI, J. S. Efeitos de verdade que emanam do discurso da inclusão e suas implicações subjetivas. In: Mal-estar na inclusão: como (não) se faz. São Paulo: Mercado de Letras, 2014.

CARNEIRO, C. O estudo de casos múltiplos: estratégia de pesquisa em psicanálise e educação. In: Psicologia USP, v.29, n.2, p.314-321, 2018.

COLlares, C. A.L.; MOYSeS, M. A. A. Preconceitos no cotidiano escolar. Ensino e Medicalização. São Paulo: Cortez, 1996.

DANTO, E. A. As clínicas públicas de Freud: psicanálise e justiça social. São Paulo: Editora Perspectiva, 2019.

DE CARLI, G. F.; FILHO, F. C. S.; CEZAR, L. O. Mal-estar na infância e medicalização do sofrimento: quando a brincadeira fica sem graça. Salvador: Ágalma, 2020.

DUNKER, C.I.L. Mal-estar, sofrimento e sintoma. São Paulo: Boitempo, 2015.

FILHO, D. M. N. Sobre a psiquiatria e a psicanálise. In: Psicofarmacologia e Psicanálise. Maria Cristina Rios Magalhães (org.). São Paulo: Escuta, 2001.

FONSECA, Paula Fontana. Para além do diagnóstico. In: Práticas inclusivas em escolas transformadoras: acolhendo o aluno-sujeito. São Paulo: Escuta, Fapesp, 2017.

FRANCO, V. Formação possível para uma profissão impossível: o professor e a sua formação psicológica. In: BERTÃO, A. M.; FERREIRA, M. S.; SANTOS, M. R. (orgs.). Pensar a escola sob os olhares da psicologia. Porto: Ed. Afrontamento, 1999. 
FREUD, S. A dinâmica da transferência. In: Edição Standart Brasileira das Obras Completas de S. Freud, v. 12. Rio de Janeiro: Imago, 1996 [1912].

FREUD, S. Linhas de progresso na terapia psicanalítica. In: Edição Standart Brasileira das Obras Completas de S. Freud, v. 17. Rio de Janeiro: Imago, 1996 [1919].

GUARIDO, R.; VOLTOLINI; R. O que não tem remédio, remediado está? In: Revista Educação em Revista, v. 25, n. 01, p.239-263, 2009.

LACAN, J. Duas notas sobre criança. Tradução de Durval Checchinato. In: Ormicar? - Revue du Champ freudien, n. 37, avril-juin 1986. Disponível em: http://www.acpsicanalise.

org.br/docs/duas-notas-sobre-crianca.pdf. Acesso em: 07 jun. 2021.

LAIA, S. A Classificação dos Transtornos Mentais pelo DSM-V e a Orientação Lacaniana. In:CliniCAPS, 5 (15), 2011. Disponível em: http://www.clinicaps.com.br/clinicaps_pdf/

Rev_15/LaiaS.pdf. Acesso em: 07 jun 2021.

LIMA, R. C. Somos todos desatentos? O TDA/H e a construção de Bioidentidades. Rio de Janeiro: Relume-Dumará, 2005.

MARIOTTO, R. M. M.; PESARO, M. E. O roteiro IRDI: sobre como incluir a ética da Psicanálise nas Políticas públicas. In: Estilos clin., São Paulo, v. 23,n. 1, p. 99-113, 2018. Disponível em: http://pepsic.bvsalud.org/scielo.php?script=sci_arttext\&pid=

S1415-71282018000100007\&lng=pt\&nrm=iso. Acesso em: 11 jun. 2021.

MELLO, L. C. Nise da Silveira: caminhos de uma psiquiatra rebelde. Rio de Janeiro: Automatica Edições; Hólos, 2014.

MOYSÉS, M.; COLLARES, C. Inteligência Abstraída, Crianças Silenciadas: as Avaliações de Inteligência. In: Psicologia USP, São Paulo, v.8, n. l, p.63-89, 1997. Disponível em: https://www.revistas.usp.br/psicousp/article/view/107579/105998. Acesso em: 11 jun. 2021.

MOYSÉS, M.; COLLARES, C. Controle e medicalização da infância. In: DESIDADES - Revista Eletrônica de Divulgação Científica da Infância e Juventude. 0(1), 2015. Disponível em: https://revistas.ufrj.br/index.php/desidades/article/view/2456. Acesso em: 11 jun. 2021.

ORRÚ, S. E. Aprendizes com autismo: aprendizagem por eixos de interesse em espaços não excludentes. Rio de Janeiro: Editora Vozes, 2016.

PASCOAL, M.; HONORATO, E. C.; ALBUQUERQUE, F. A. O orientador educacional no Brasil. In: Educação em Revista [online], n. 47, 2008. Disponível em: https://doi.org/

10.1590/S0102-46982008000100006. Acesso em: 11 jun. 2021.

PATTO, M. H. S. Para uma crítica da razão psicométrica. In: Psicologia USP, 8 (1), p. 47-62, 1997.

PATTO, M.H.S. A produção do fracasso escolar: histórias de submissão e rebeldia. São Paulo: Intermeios, 2015.

PESARO, M. E. et al. Efeitos da intervenção institucional: da agitação motora ao brincar simbólico. In: Psicanálise e Ações de prevenção na primeira infância. São Paulo. Editora Escuta/Fapesp, 2012. 
REIS, B. M.; CECÍLIO, S. Precarização, trabalho docente intensificado e saúde de professores universitários. In: Trabalho \& Educação. Belo Horizonte, v.23, n.2, p.109-128, 2014. Disponível em https://periodicos.ufmg.br/index.php/trabedu/article/view/9141/6566. Acesso em: 10 jun, 2021.

REZENDE, T. C.; SÁ, V. R.G. Infância, Liberdade e Acolhimento: experiências na educação infantil. São Paulo: Summus Editorial, 2018.

RIBEIRO, M. P. Contribuição da psicanálise para a educação: a transferência na relação professor/aluno. In: Psicol. educ., São Paulo, n. 39, p. 23-30, 2014. Disponível em: http://pepsic.bvsalud.org/scielo.php?script=sci_arttext\&pid=S1414-69752014000200003. Acesso em: 23 fev. 2021.

SAFATLE, V. O poder da psiquiatria. In: Cult: São Paulo, n.184, 2013.

VERAS, M. Selfie, logo existo. Salvador: Corrupio, 2018.

VOLTOLINI, R. Educação e psicanálise. Rio de Janeiro: Jorge Zahar, 2011.

WINNICOTT, D.W. Os bebês e suas mães. São Paulo: Ubu Editora, 2020.

Recebido em: 21/03/2021

Aprovado em: 07/06/2021 